\title{
Bioactive properties of insect products for monogastric animals - a review
}

\author{
T. Veldkamp ${ }^{1 *}$ iD, L. Dong ${ }^{2,3}$, A. Paul ${ }^{4}$ and C. Govers ${ }^{2,5}$ \\ ${ }^{1}$ Wageningen Livestock Research, De Elst 1, 6700 AH Wageningen, the Netherlands; ${ }^{2}$ Wageningen Food and Biobased \\ Research, Bornse Weilanden 9, 6708 WG Wageningen, the Netherlands; ${ }^{3}$ Food Chemistry, Wageningen University, Bornse \\ Weilanden 9, 6708 WG Wageningen, the Netherlands; ${ }^{4}$ Protix B.V., Industriestraat 3, 5107 NC Dongen, the Netherlands; ${ }^{5}$ Cell \\ Biology E Immunology, Wageningen University, De Elst 1, 6700 AH Wageningen, the Netherlands; teun.veldkamp@wur.nl
}

Received: 19 February 2021 / Accepted: 6 May 2021

(c) 2021 Wageningen Academic Publishers

\begin{abstract}
OPEN ACCESS CC (i)
RESEARCH ARTICLE

\section{Abstract}

Insects or products derived from insects are considered as a valuable feed ingredient for aquaculture, poultry, and pigs but also exert possible secondary effects of health stimulators in livestock as reported in literature. Health benefits attributed to insects can create additional value in the insect chain. Three categories of bioactive compounds in insects are reported in this desk study: antimicrobial peptides (such as $\alpha$-helical peptides, cysteine-rich peptides, proline-rich peptides, glycine-rich peptides), fatty acids (especially lauric acid), and polysaccharides (especially chitin and chitosan). The review summarises the recent literature on these three categories. Antimicrobial properties or immuno-modulating effects may contribute to reduce the use of antibiotics and to avoid antibiotic resistance in livestock when these insect products are included in animal diets. Furthermore, antioxidant capacity of insectproteins might reduce collateral tissue damage. Health stimulating effects of insect products may result in additional applications of insect products in animal feed for livestock.
\end{abstract}

Keywords: antioxidant activity, bioactive insect compounds, chitin, fatty acids, peptides

\section{Introduction}

The availability and use of antimicrobials in farm animals are essential for health and productivity. It contributes to food security and animal welfare, which in turn helps protect farmers' livelihoods and animal sustainability (FAO, 2016). Most antibiotics are small cationic proteins that are active against bacteria and/or fungi and certain parasites and viruses (Yi et al., 2014). It is estimated that the global consumption of antibiotics by the livestock industry in 2010 was at least 63,000 metric ton (Van Boeckel et al., 2015) and the authors estimated that global consumption of antibiotics in agriculture will increase by $67 \%$ from 2010 to 2030. There is growing concern on the application of these high amounts of antibiotics as over-use of antibiotics has led to the development of antimicrobial resistance (AMR) by pathogens in husbandry (Llor and Bjerrum, 2014). Antimicrobial resistance concerns microorganisms bacteria, fungi, viruses, and parasites - that have acquired resistance to antimicrobial substances. The consequences of AMR include failure to successfully treat infections, leading to increased mortality, more severe or prolonged illness, production losses, and reduced livelihoods and food security. Moreover, AMR is a threat for humans as demonstrated by a comprehensive survey of antibiotic resistance in poultry products in the United States (Simjee et al., 2002). Enterococcus faecium isolates from these poultry products were shown to be highly resistant to penicillin, tetracycline, and erythromycin. At present, the development of AMR has been addressed by restricting the use of antibiotics in the feed industry, agriculture, and veterinary medicine. However, this only provides a temporary solution, and research is ongoing to identify alternatives to antibiotics. These alternatives must be sustainable and appropriately address animal health and welfare issues.

Insects can fulfil a major role in upgrading the value of side streams or leftovers into high-value feed ingredients in a circular economy. Insect farming has some environmental advantages compared to livestock production such as less land and water usage, lower greenhouse gas emissions, and 
high feed conversion efficiencies (Van Huis and Oonincx, 2017). Reviews on the nutritional value of insect products indicate their potential applications as alternative protein sources in different livestock diets (Dörper et al., 2021; Jozefiak et al., 2016; Makkar et al., 2014; Sanchez-Muros et al., 2014; Veldkamp et al., 2012). Insects at all life stages are rich sources of macro-nutrients such as protein and fat (Bovera et al., 2016), but also other important nutrients such as mono-unsaturated and/or poly-unsaturated fatty acids, copper, iron, magnesium, manganese, phosphorous, selenium, and zinc, as well as riboflavin, pantothenic acid, biotin, and in some cases, folic acid (Rumpold and Schlüter, 2013). Moreover, many bioactive compounds from insects are shown to, or putatively, have an antimicrobial activity or immunomodulatory effect such as antimicrobial peptides (Hu et al., 2017; Jozefiak and Engberg, 2017; Wang et al., 2016), fatty acids and especially lauric acid (Kabara et al., 1972), polysaccharides and especially chitin/chitosan (Dong et al., 2020). Currently, available volumes of insect products are low, costs of insect products are relatively high compared to conventional protein sources, and there are still some legislative issues to be solved for a large implementation of insect products as feed ingredients in the livestock sector. Health benefits attributed to insects can create added value in the insect chain and support their use in feed. Intact, ground insects, or even processed insect products fed to livestock can improve animal health and may help reduce the use of antibiotics in the livestock chain (Gasco et al., 2018).

This paper focuses on the beneficial health effects of insects and in particular on antimicrobial, immunomodulatory and antioxidant effects of peptides, fatty acids, and polysaccharides found in insects for their usage in monogastric animals.

\section{Antimicrobial peptides}

Antimicrobial peptides (AMPs) work by destructing the bacterial cell envelope. Most AMPs are cationic molecules, which disturb the target cell membrane by forming ion channels or transmembrane pores, thereby killing bacterial cells (Park and Hahm, 2005). The primary targets of AMPs are lipids in the bacterial cell membrane. AMPs bind to the anionic phospholipids and phosphate groups of the lipopolysaccharides (LPS) of Gram-negative bacteria, as well as to the peptidoglycan layer of Gram-positive bacteria. The effectiveness of their antimicrobial activity depends mainly on the lipid composition and the negative electric potential of the target membrane.

Four different models of disrupting the bacterial cell membrane by AMPs have been described (Duclohier, 2002). The first model of AMP action is the barrel-stave model, in which peptides bind to the cell membrane and insert themselves into the hydrophobic core of the membrane.
This results in the formation of pores and causes leakage of cytoplasmic material and a decrease in membrane potential. In this way, membrane-damaging peptides (such as gramicidin) can disrupt the ionic homeostasis of cells, leading to cell dysfunction and cell death. The second model is the toroidal model, in which peptides accumulate in a lipid monolayer and form pores, ultimately leading to the destruction of bacterial cells. Barrel stave pores interact with the bilayer hydrocarbon core, using it as a template for peptide self-assembly, whereas toroidal pores interact against the hydrocarbon core, disrupting the normal segregation of polar and nonpolar parts of the membrane by providing alternate surfaces for lipid hydrocarbon and headgroups to interact favourably with (Wimley, 2010). In the third model, AMPs cover the cell membrane in a carpet-like manner. This effect requires high AMP concentration and causes cell membrane dissolution. An example of a well described AMP acting in this way is the cecropin family. Cecropin is always oriented parallel to the membrane surface. The fourth and final strategy is to disrupt the cell membrane by creating 'unstructured ring pores' (i.e. aggregation channels) (Duclohier, 2002). This manner of AMP-mediated cell membrane disruption is similar to the activity of detergents (Wimley, 2010). In addition to these models of membrane destruction, some AMPs, such as proline-rich AMPs, may exert antibacterial activity by intervening in intracellular processes. It has been suggested as a general rule, that AMPs that act at high concentrations do so by permeabilising or destroying microbial membranes, while AMPs that act at low to moderate concentrations interact with intracellular targets (Nicolas, 2009). To demonstrate the effectiveness of antimicrobial substances from black soldier fly (BSF) Hermetia illucens (L.) (Diptera: Stratiomyidae) larvae, the larvae were septically injured with a contaminated needle (Park et al., 2014). Subsequently, BSF larvae were lyophilised, homogenised, and peptides and other small molecules were extracted with acidic methanol. The acidic methanol extraction method was used for the extraction of antimicrobial substances from the larvae, because the acidic methanol could denature and precipitate large proteins and polypeptides, while efficiently extracting small molecules (Meylaers et al., 2003). The antifungal and antibacterial effects of low molecular weight antimicrobial factors were examined on the growth of a wide range of microorganisms, including Gram-positive Staphylococcus aureus, methicillin-resistant S. aureus (MRSA), and Gramnegative Pseudomonas aeruginosa. The BSF larval extract possessed a broad spectrum of antibacterial activity, demonstrating that secretions from BSF larvae prove useful in the fight against MRSA. In literature, different insect bioactive peptide families have been described and the mode of action of these peptides resulting in antimicrobial effects in vitro or in vivo in monogastric animals have been discussed. In the following paragraphs specific AMPs are discussed. 


\section{a-helical peptides - cecropins}

Among the many peptides synthesised by insects, cecropins are the best known $\alpha$-helical cationic antimicrobial peptides and hence is one of the most widely studied antimicrobial peptides (Duvic et al., 2012). They were initially isolated from the haemolymph of experimentally infected and diapaused pupae of the moth Hyalophora cecropia (L.) (Lepidoptera: Saturniidae) (Steiner et al., 1981). Since the first report, the expression of cecropin-like peptides has been recorded in many other insect species, all of which belong to the higher insect orders of the Diptera and Lepidoptera. (Bulet et al., 2003). Cecropins were also identified in Drosophila melanogaster Meigen (Diptera: Drosophilidae), Aedes aegypti (L.) (Diptera: Culicidae), Anopheles gambiae Giles (Diptera: Culicidae), Musca domestica L. (Diptera: Muscidae), Bombyx mori L. (Lepidoptera: Bombycidae), and Helicoverpa armigera Hübner (Lepidoptera: Noctuidae) (Jin et al., 2010). It was uncertain whether cecropins had a wider distribution among insects until cecropins were identified in Ascaris nematodes and tunicates. A cecropin-like 31 residue peptide (cecropin P) has been isolated from the small intestine of a pig (Lee et al., 1989), suggesting that the cecropins may be widespread throughout the animal kingdom. Mature cecropin peptides lack cysteine residues, are 35-39 amino acids in length, and form two linear alpha helices connected by a hinge. These helices integrate into the acidic cell membrane of bacteria, causing its destruction (Charroux et al., 2009; Imamura et al., 2009; Tanaka et al., 2005). Cecropins are active against both Gram-positive and Gram-negative bacteria (Otvos, 2000). Examples of in vivo antimicrobial effects of cecropins are presented hereafter.

The synthetically produced anti-microbial cecropin peptide P5 is an exemplary peptide that was used as an alternative to antibiotics as a growth promoter in broilers (Choi et al., 2013b). The authors investigated the effects of dietary supplementation of the antimicrobial peptide P5 (AMP-P5) on growth performance, nutrient retention, excreta, intestinal microbiota, and morphology in broilers. The effect of the AMP-P5 experimental diet containing 40 or $60 \mathrm{mg}$ AMP-P5/ $\mathrm{kg}$ was compared to the negative control (basic diet without antimicrobials) and the positive control (basic diet supplemented with $15 \mathrm{mg}$ avilamycin/kg diet). Body weight gain, dry matter, and nitrogen retention were improved in broilers fed the positive control and the AMP-P5 diet compared to chickens fed the negative control. Increasing the AMP-P5 dietary level linearly improved weight gain, feed conversion rate, dry matter, and nitrogen retention. The total anaerobic bacteria and coliforms in the excreta and the coliforms in the ileal and caecal digesta were reduced in broilers fed the positive control diets and $60 \mathrm{mg}$ of AMP-P5 compared to the broilers fed the negative control diet. Furthermore, the height of the villi in the duodenum and jejunum and the ratio of villi height to crypt depth in the duodenum, jejunum, and ileum increased in birds fed the positive diet and $60 \mathrm{mg}$ AMP-P5 compared to broilers fed the negative control diet. Together, these results indicate that dietary supplementation with $60 \mathrm{mg}$ AMP-P5/kg has the potential to improve the growth performance, nutrient retention, and intestinal morphology, and reduce intestinal and excreta coliforms in broilers similar to antibiotics. In a similar experimental setup, the inclusion of 60 or $90 \mathrm{mg}$ of the synthetically produced antimicrobial peptide A3 (AMP-A3) was tested (Choi et al., 2013a). Broilers demonstrated increased growth performance and showed improved intestinal morphology and microbiota balance when fed this cecropin peptide. Wen and He (2012) evaluated the feasibility of including the antimicrobial peptide cecropin $\mathrm{A}(1-11)-\mathrm{D}(12-37)-$ Asn $(\mathrm{CADN})$ in poultry diets instead of antibiotic growth promoters (AGP). Chimeric CADN was originally isolated from $H$. cecropia (L.) (Lepidoptera: Saturniidae). At micromolar concentrations, it has strong antibiotic activity against Gram-positive and Gramnegative bacteria. Chimeric CADN has the first 11 amino acid residues of the $\mathrm{N}$-terminus of cecropin $\mathrm{A}$ and the last 26 amino acid residues of the $\mathrm{C}$-terminus of cecropin $\mathrm{D}$, and shows greater antibacterial activity compared with individual parental peptides. A total of 1,500 male chickens at 14 days of age were randomly assigned to five groups and fed ad libitum with grower diets followed by fattening diets for 14 days each. The diets consisted of basal diets supplemented with a liquid sample of CADN (CADNL) at $0,2,4,6$, or $8 \mathrm{ml} / \mathrm{kg}$ for the five different diets. During the feeding period, a metabolic experiment was performed to determine the apparent digestibility of diethyl ether extract, nitrogen retention, and the apparent metabolisable energy of the feed sample fed to each chick cage. At the end of the feeding experiment, one chick was sacrificed from each cage for bacteriological, light microscopic and scanning electron microscopic examination of the intestinal villi. Chimeric CADN had a negative linear effect on feed intake $(\mathrm{F})$ and feed:gain ratio $(\mathrm{F}: \mathrm{G})$ and a positive quadratic effect on weight gain $(G)$ for grower diets. Chimeric CADN had a quadratic effect on F, G, or F:G for the finisher diets and nutrient utilisation was increased for both grower and finisher diets. Chimeric CADN decreased the counts of aerobic bacteria in the jejunal and caecal digesta in a dose-dependent manner and increased the height of the intestinal villi in a dose-dependent manner and caused the duodenal villi of the CADNL8 group at 42 days to appear as a leaf-shaped structure. The authors concluded that CADN may therefore be a substitute for antimicrobial growth promoter in broiler feed. For implementation in animal feed, however, it would also be interesting to see if grinded H. cecropia (L.) (Lepidoptera: Saturniidae) would also be effective for AMP activity. 


\section{a-helical peptides - coprisin}

Kang et al. (2011) studied the antibacterial effect of coprisin in mice. The authors isolated coprisin, an antimicrobial peptide from the Korean dung beetle Copris tripartitus (Coleoptera: Scarabaeidae), and identified a nine amino acid peptide in its $\alpha$-helix region (LLCIALRKK) that contained antimicrobial activity. In a mouse model of acute intestinal inflammation, established by the administration of antibiotics followed by Clostridium difficile infection, the treatment effects of a coprisin analogue (disulphide bond dimer of nine peptides) were examined. Treatment with this coprisin analogue significantly alleviated weight loss, improved survival, and reduced mucosal damage and the production of pro-inflammatory cytokines. In contrast, the coprisin analogue showed no apparent antibiotic activity against commensal bacteria, including Lactobacillus and Bifidobacterium, which are known to inhibit C. difficile colonisation (Kang et al., 2011). The results indicated that the coprisin analogue may be useful as a therapeutic agent for inflammatory diarrhoea associated with $C$. difficile infection and pseudomembranous colitis in mice.

\section{Cysteine-rich peptides - insect defensin}

Among naturally occurring antibiotic peptides, defensins form a unique family. They have in common that they are cationic, structured polypeptides, composed of 34-51 amino acids rich in cysteine with three or four disulphide bridges. Defensins have been isolated from mammals, insects, and plants (Thevissen et al., 2004). They act as effector molecules of innate immunity and provide an effective initial defence against infectious pathogens. The structure of the defensin-like peptide has been determined, and the basic structural similarity between family members suggests that the overall structure is robust and that the nature of the side chains determines the specific functionality (Torres and Kuchel, 2004). They have been identified in many insect species of Diptera, Hymenoptera, Coleoptera, Lepidoptera, Hemiptera, Isoptera, and Pteroptera (Yi et al., 2014). In insects, these peptides are produced by fat body cells and haemolymph cells, and they can easily diffuse and act systematically. The insect haemolymph acquires antimicrobial properties after the insect has been injured or after a microbial infection. Insect defensins are active mainly against Gram-positive bacteria (Otvos, 2000), including Micrococcus luteus, Aerococcus viridians, Bacillus megaterium, Bacillus subtilis, Bacillus thuringiensis, and S. aureus. Some insect defensins are also active against Gram-negative bacteria such as Escherichia coli (Yi et al., 2014), or fungi, yeasts, and protozoa (Chapuisat et al., 2007; Viljakainen and Pamilo, 2008). To better understand the functional domains of defensins in general, the tenecin-1 defensin was studied in more detail by Lee et al. (1998). When induced in the haemolymph of Tenebrio molitor $\mathrm{L}$. (Coleoptera: Tenebrionidae) larvae, tenecin-1 was effective against Gram-positive bacteria, especially methicillinresistant S. aureus (MRSA) (Moon et al., 1994). Moreover, activity against Staphylococcus epidermidis, Staphylococcus pyrogen, $M$. luteus, and Corynebacterium diphtheriae but also against fungi have also been established (Jozefiak et al. (2016). A reduced version of tenecin-1 was created, to investigate the functionality of the disulphide bridges, and a chemically synthesised N-terminal loop-deleted tenecin-1 was designed and both compared in activity to the native peptide. The native peptide showed strong antimicrobial activity; however both modified versions showed no antimicrobial effects, indicating that three disulphide bridges and the $\mathrm{N}$-terminal loop are necessary for the bactericidal activity. Park et al. (2015) induced and purified a novel defensin-like peptide 4 (DLP4) from the immunised haemolymph of BSF larvae. The larvae were first washed with water containing disinfectant and rinsed with deionised water. Excess water was removed, after which each larvae was pricked deeply with a fine needle dipped into S. aureus (KCCM 40881; OD600=2.4). The immunised haemolymph was extracted and DLP4 was purified by solid phase extraction and reverse phase chromatography. Minimum inhibitory concentration (MIC) analysis showed that DLP4 had antibacterial activity against Gram-positive bacteria, including MRSA. Interestingly, transcription of the DLP4 gene hardly occurred in the body without compromising health, but upon bacterial challenge the expression of DLP4 transcripts was measured by quantitative real-time PCR in several tissues. Transcription was most pronounced in the fat body after immunisation. Commercially produced sterile bottle green flies Lucilia sericata Meigen (Diptera: Calliphoridae) maggots have been used successfully by medical professionals around the world to clean many chronic necrotic wounds and reduce bacterial burden on wounds during Maggots Debridement Therapy. Maggot secretions contain antibacterial activity and other activities beneficial to wound healing. Several secreted components of insect immunity were identified, including a defensin named lucifensin. This was produced recombinantly as a Trx-fusion protein in E. coli, purified using immobilised metal affinity chromatography and reverse-phase HPLC, and tested in vitro against Grampositive and Gram-negative bacterial strains. Lucifensin was active against the Gram-positive bacterial strains Staphylococcus carnosus, Streptococcus pyogenes, and Streptococcus pneumoniae, as well as S. aureus. The peptide did not show antimicrobial activity towards Gram-negative bacteria. Schmitt et al. (2016) discussed that amino acid residues in the peptide affects the molecular interaction at the bacterial membranes and subsequent antibacterial activity against Gram-positive and Gram-negative bacterial strains. Lucifensin has demonstrated antimicrobial activity comparable to other defensins and may have potential as a future scaffold for drug candidates, to be redesigned for other uses besides topical treatment of infected wounds (Andersen et al., 2010). 


\section{Proline-rich peptides}

Proline-rich AMPs, which are isolated from mammals and insects, are mainly active against Gram-negative bacteria, including a wide variety of plant-derived bacteria and some human pathogens (Liu et al., 2007; Otvos, 2000). All prolinerich (PR) peptides isolated from mammals belong to the cathelicidin family of AMPs, such as PR-39 and prophenin. They constitute a group of vertebrate and invertebrate host defence cation peptides characterised by a high content of proline residues, often associated with arginine residues in repeating motifs. Insect-derived proline-rich AMPs are usually 20-35 amino acid residues in length, penetrate and pass through the outer membrane and enter the periplasmic space. In the cell, the peptides impede intracellular processes, such as the transport system (Scocchi et al., 2011). Due to their special properties, they are classified as potential cell-penetrating peptides, capable of internalising impermeable drugs into bacteria and eukaryotic cells. Many proline-rich peptides were described by Otvos (2002). A characterised proline-rich AMP is drosocin, which appears to kill susceptible bacterial species (E. coli) by inhibiting the chaperone protein DnaK. (Kragol et al., $2001,2002)$. Drosocin is the prototype for medium-sized proline-rich antibacterial peptides that have been isolated from Hymenoptera, Lepidoptera, Hemiptera, and Diptera. (Bulet et al., 1993). Proline-rich AMPs can also interfere with the synthesis of DNA and RNA by binding to nucleic acids (Kragol et al., 2002; Li et al., 2006; Nicolas, 2009) and have been shown to exert antimicrobial effects in $E$. coli, Klebsiella pneumoniae, P. aeruginosa, and Acinetobacter baumannii (Hansen et al., 2012; Mattiuzzo et al., 2007). Apidaecins are a separate group of proline-rich peptides and may be used as new candidates for peptide antibiotics as they contain improved membrane penetration capacity (Li et al., 2006). They are lethal to many Gram-negative bacteria. The mechanism of action by which apidaecins kill bacteria involves an initial nonspecific encounter of the peptide with a component of the outer membrane, followed by invasion of the periplasmic space. Apidaecins then cross the inner membrane by specific and essentially irreversible coupling with a receptor or docking molecule (most likely a component of a permease-type transporter system). In the last step, the peptide is transported inside the cell, where it reaches its final target (most probably DnaK protein), and then performs its antibacterial function. For example, it can inhibit the two main functions of DnaK (E. coli HSP70), being ATPase activity and protein folding (Wu et al., 2020).

\section{Glycine-rich peptides}

The family of antimicrobial peptides rich in glycine usually targets fungi, Gram-negative bacteria (Otvos, 2000), and cancer cells by destroying cell membranes (Lee et al., 2007). AMPs rich in glycine residues (14-22\%), such as sarcotoxin IIA, hymenoptaecin, attacin, diptericin, and coleoptericin, have been identified in different insect species (i.e. B. mori L. (Lepidoptera: Bombycidae), Glossina morsitans Westwood (Diptera: Glossinidae), Heliothis virescens Fabricius (Lepidoptera: Noctuidae), Trichoplusia $n i$ Hübner (Lepidoptera: Noctuidae), Samia cynthia ricini Drury (Lepidoptera: Saturniidae), and M. domestica L. (Diptera: Muscidae) (Dushay et al., 2000; Geng et al., 2004; Li et al., 2012). The high amount of glycine residues in these AMPs has a major impact on the tertiary structure of these peptides and their mode of action. Attacins, for example, act through blocking the synthesis of the major outer membrane proteins in dividing Gram-negative bacteria, such as $E$. coli, thus disturbing the integrity of the cell wall and causing the bacteria to grow in long chains (Carlsson et al., 1998).

\section{Insect AMP-complexes}

In recent decades, much attention has been paid to AMPs as natural antibiotics that are likely to be protected against the development of bacterial resistance. However, experimental evolution studies have revealed a rapid increase in the resistance of bacteria to tested individual AMPs (Chernysh et al., 2015). In terms of the development of drug resistance, complexes of insect AMPs have an obvious advantage over individual peptides and small molecule antibiotics. Combining AMPs with a different mode of action will reduce the risk for resistance to bacteria. This strategy is also used in chemical bactericides. As a model to demonstrate the potency of AMP complexes, a semi-purified AMP complex from bacteria-challenged maggots of Calliphoridae flies was used (Chernysh et al., 2015). The isolated AMP complex was found to contain three different families of membrane damaging or permeable peptides (defensins, cecropins, and diptericins), one proline-rich peptide family and several unknown antimicrobial substances. The clinical strains of E. coli, K. pneumoniae, and A. baumannii were used to test the resistance to the isolated AMP complexes and reference antibiotics cefotaxime, meropenem, and polymyxin B. All strains easily developed resistance to the reference antibiotics, while no signs of increased resistance to the AMP complex consisting of defensins, cecropins and diptericin, and proline-rich peptides were recorded. Similar results were obtained with the compounds isolated from three other fly species (i.e. Calliphora vomitoria (L.) (Diptera: Calliphoridae), L. sericata Meigen (Diptera: Calliphoridae), and M. domestica L. (Diptera: Muscidae)). Rahnamaeian et al. (2015) also showed the functional synergy of co-occurring insect AMPs (the bumblebee linear peptides hymenoptaecin and abaecin) resulting in more potent antimicrobial effects at low concentrations. Abaecin showed no detectable activity against $E$. coli when tested alone at concentrations up to $200 \mathrm{mM}$, while hymenoptaecin influenced the growth and viability of bacterial cells, but only at concentrations above $2 \mathrm{mM}$. When combined, 
just $1.25 \mathrm{mM}$ abaecin enhanced the bactericidal effect of hymenoptaecin. These naturally occurring synergistic interactions suggest that AMP combinations can be used therapeutically against Gram-negative bacterial pathogens that have acquired resistance to common antibiotics.

\section{Fatty acids}

Fatty acids with aliphatic tails of six to twelve carbon atoms are called medium-chain fatty acids (MCFAs) and have also demonstrated antimicrobial activity. In some cases, the effect on the intestinal mucosa and the antibacterial activity of MCFA may be beneficial for the prevention and treatment of gastrointestinal diseases in piglets after weaning (Rossi et al., 2010). Medium-chain fatty acids can be used directly by enterocytes for energy production, thus helping to support gut integrity in young piglets (Guillot et al., 1993). Recent research in pigs indicates that certain fatty acids, including short- and medium-chain fatty acids and long-chain polyunsaturated fatty acids, play a potential therapeutic role in pig enteritis (Liu, 2015). The results of these studies indicate that fatty acids have an impact on the intestinal integrity of pigs. Utilising these feeding strategies can offer a significant opportunity to improve pig health and nutrient efficiency in human food production. MCFAs are naturally found in milk fat and in various feed materials, especially in coconut and palm oils. In addition to these raw materials, it is also known that insects such as BSF prepupae can contain high levels of the MCFA lauric acid and it is possible that insect oil can replace the less sustainable fat sources in animal feed.

\section{Lauric acid}

Black soldier flies contain fatty acids at levels ranging between $15-49 \%$ on dry matter basis (Makkar et al., 2014). The fatty acid composition of the larvae depends on the fatty acid composition of the diet. Lauric acid (C12:0) has been found in high concentrations (up to 60\%) in the fat of the prepupae of BSF reared in organic waste streams with high amounts of starch (Spranghers et al., 2017). The lipids of cow manure-fed larvae contained $21 \%$ lauric acid, $16 \%$ palmitic acid, $32 \%$ oleic acid, and $0.2 \%$ omega- 3 fatty acids, with the proportions being $43,11,12$, and $3 \%$ for the larvae, respectively, fed a mixture of $50 \%$ fish offal and 50\% cow manure (St-Hilaire et al., 2007). Lauric acid is known for its antiviral and antibacterial activities (Lieberman et al., 2006), in particular its activity against Gram-positive bacteria (Skřivanová et al., 2005). Skřivanová et al. (2005) determined the susceptibility of Clostridium perfringens strains CCM 4435T and CNCTC 5459 to $\mathrm{C} 2-\mathrm{C} 18$ fatty acids. Lauric acid showed the highest antimicrobial activity, followed by myristic, capric, oleic, and caprylic acid. Lauric acid activity was not influenced by the presence of solid particles and did not cease at $\mathrm{pH}>6$. Significant antibacterial activity of lauric acid was also seen in pigs with D-streptococcal infections (Spranghers et al., 2018). At the highest inclusion level (equivalent to $0.87 \mathrm{~g}$ of $\mathrm{C} 12: 0 / 100 \mathrm{ml}$ ), reductions of approximately 2 logs of D-streptococci were observed. In the animal test, only $0.5 \log$ cfu reductions of D-streptococci were observed in the gut of piglets fed diets containing $8 \%$ full-fat BSF. The authors discussed that most of the lauric acid from the feed was absorbed too early (57-60\% already in the stomach) and could not reach the places where it would find the optimal conditions to inhibit bacterial growth. It is worth noting that monolaurin can be formed as a monoester from lauric acid and is many times more biologically active than lauric acid in killing viruses and bacteria (Lieberman et al., 2006). Although the mode of action of MCFA is not fully understood, it is known that its antibacterial activity is related to the decrease in $\mathrm{pH}$ and its dissociation ability (Roth and Kirchgessner, 1998). Undissociated forms of MCFA can penetrate the lipid membrane of the bacterial cell and then dissociate in the cytoplasm. As the target bacteria struggle to maintain a neutral $\mathrm{pH}$ by exporting excess protons, cellular ATP is consumed leading to energy depletion and ultimately leading to cell death (Ricke, 2003). In an in vitro evaluation, the high amount of $\mathrm{C} 12: 0$ in the fat extracts of the prepupae of BSF resulted in substantial antimicrobial effects against D-streptococci, while no significant effects were recorded for coliforms (Spranghers et al., 2018). Lauric acid, however, also demonstrated a low impact on the commensal Lactobacilli in humans (Matsue et al., 2019) suggesting that lauric acid might modulate intestinal health by managing the microbiota in the upper small intestine, in which bacteria are mainly Gram-positive bacteria. The possible antimicrobial effects of BSF fat (C12: 0 ) could provide important added value when whole larvae or prepupae are used as a protein source in monogastric feeding (Spranghers et al., 2017). The antimicrobial activity of BSF fat can provide a significant added value when complete pre-pupae are used as a protein source in feed for monogastric animals (Spranghers et al., 2018). Moreover, extracted fat of insects as oil source can maybe replace less sustainable vegetable oil sources currently used in animal diets.

\section{Polysaccharides}

Chitin and chitosan are polysaccharides that are found in high concentrations in insects. Chitosan is an edible, biodegradable polymer which is the main organic skeleton material of the arthropod exoskeleton, including insects, crustaceans, and some fungi (Cutter and Sumner, 2002; Mau-Chang et al., 1996; Suyatma et al., 2004). Chitosan, $\beta$-(1-4)-linked 2-amino-2-deoxy- $\beta$-D-glucopyranose, is an $\mathrm{N}$-deacetylated derivative of chitin, in which acetamide groups were converted into primary amino groups (Islam et al., 2017). Chitosan is, next to cellulose, the most common natural polymer (Vartiainen et al., 2004). Chitosan not only acts as a chelating agent in biological systems, but also has 
antibacterial activity against bacteria, yeasts, and fungi (Vartiainen et al., 2004). Furthermore, fish, birds, or mammals cannot synthesise chitin or chitosan, so they are a potential target for recognition by the immune system (Komi et al., 2018). In fact, innate immune cells can be stimulated by chitin and chitosan (Lee et al., 2008) and the presence of chitin in the exoskeletons of insects and larvae may affect the immune status of monogastric animals (Islam and Yang, 2017). For example, broiler chickens fed with T. molitor larvae were shown to have a lowered albumin/ globulin ratio, which indicated that immune activity was enhanced (Bovera et al., 2015). Similar results were found for laying hens fed approximately $1 \mathrm{~g}$ per day of chitin provided by the inclusion of BSF larval meal in the diet (Marono et al., 2017). Chitin's positive effects on laying hens health and metabolism are also confirmed by Bovera et al. (2018). In the experiment BSF larval meal was fed at two different levels in substitution ( 25 or $50 \%$ ) of soybean meal to laying hens. Hens fed the higher amount of insect meal showed higher values of globulin and a lower albumin/ globulin ratio compared to the other groups. High globulin concentrations and low albumin/globulin ratios indicate a better disease resistance and immune response in birds (Griminger and Scanes, 1986). These findings for better disease resistance and immune response were also confirmed by high globulin concentrations and low albumin/globulin ratios in an experiment with partridges fed two different levels of BSF larvae as well as T. molitor in substitution ( 25 or $50 \%$ ) of soybean meal (Loponte et al., 2017). Broiler trials demonstrated the antimicrobial activity of chitin. Broilers provided with shrimp chitin showed growth inhibition of E. coli and Salmonella enteritidis (Khempaka et al., 2011). Furthermore, fermented T. molitor larval meal or Zophobas morio Fabricius (Coleoptera: Tenebrionidae) also reduced the growth of $E$. coli and S. enteritidis in broilers. Regarding the latter study, the authors could not discriminate between chitin- and probiotics-mediated antimicrobial activity (Islam and Yang, 2017). In a follow-up analysis, the authors evaluated the antimicrobial efficacy of $0.4 \%$ dry T. molitor (DMLP) or $Z$. morio larvae (DSMLP) and their use as an alternative to antibiotics in broilers. Broilers were orally inoculated with $2.4 \times 10^{7} \mathrm{cfu}$ S. enteritidis KCTC 2021 and $3.7 \times 10^{7} \mathrm{cfu} E$. coli KCTC 2571. One week later, the mortality rate decreased after supplementation with DMLP and DSMLP. Both the average daily gain and the average daily feed intake increased and the feed conversion decreased. Detailed analysis revealed that the content of caecal $E$. coli and $S$. enteritidis was significantly reduced in broilers fed DMLP and DSMLP, while the content of faecal microbiota and the $\mathrm{pH}$ of the caecal and faecal digesta was not affected. Islam and Yang (2017) concluded that dietary supplementation with DMLP and DSMLP increased average daily body weight gain, improved feed conversion ratio and decreased mortality and caecal E. coli and S. enteritidis contents. In addition to the observed antimicrobial activities, cholesterol and triglyceride serum levels in birds were also lowered when fed diets containing BSF compared to those fed a diet based on soybean meal. Indeed, chitin has further hypolipidaemic and hypocholesterolaemic properties (Koide, 1998) in broiler chickens, resulting in a reduction in body fat and possibly the production of leaner meat (Hossain and Blair, 2007). In mice, similar studies have been performed, but with isolates of chitin or chitosan, which allows more direct correlations of the antimicrobial effects towards these compounds. In a study analysing the effects on Candida albicans infections, pre-treatment with i.p. injections of chitin and, in particular, chitosan increased survival rates (Suzuki et al., 1984). Similarly, chitosan pretreatment also increased mice survival infected with $S$. aureus (Moon et al., 2007). Chitin and chitosan, in addition to their antimicrobial activity, also showed antiparasitic activity. Infections with L. major in mice were treated with local injections of chitin or chitosan for several weeks (Hoseini et al., 2016). It was found that chitin and chitosan significantly reduced the onset of parasite-induced lesions, and upon sacrifice it was evident that they also significantly reduced the parasitic load in the draining lymph nodes. In another study chitosan was tested to treat intestinal infections with Eimeria papillata (Abdel-Latif et al., 2016). Daily gavage for 5 days significantly reduced the number of oocytes found in faeces and significantly reduced the number of parasites per crypt and significantly improved histological features. It must be stated here that insectderived compounds will not be used via injections in monogastric livestock animals but the above studies were included here to illustrate the direct effects of isolates of chitin or chitosan. The mechanism by which chitin and chitosan exert their antimicrobial and antiparasitic effects is directly or indirectly through supporting immune activity. The direct approach is presumably similar to that described for peptides and includes cell lysis, penetration of cytoplasmic membranes, and cation chelation (Park and Kim, 2010). These mechanisms could explain antimicrobial and antifungal effects but are less likely to result in antiparasitic effects. Furthermore, pilot studies now show that the antimicrobial effect could even be pathogen-specific, ruling out generic methods of action. A striking conclusion from the described, but also other studies as reviewed elsewhere (Dong et al., 2019), is the apparent difference in effectivity between chitin and chitosan. Chitosan was shown to be more effective in treating microbial infections, while chitin was more effective in treating parasitic infections. All the studies on chitin and chitosan described above had in common that they also investigated and discovered treatment-induced changes in the immune system that might have contributed to the effectiveness of the intervention. The observed decrease in growth of $E$. coli and S. enteritidis after intervention with T. molitor or Z. morio isolates coincided with an increase in IgG and IgA levels, which play a protective role against microbial infections (Islam and Yang, 2017). In studies showing that chitin and 
chitosan have a protective effect on C. albicans infection, the increase in survival rate coincides with the increase in polymorphonuclear leukocyte levels in blood and peritoneal immune cells. These cells also show an enhanced ability to produce reactive oxygen species (Suzuki et al., 1984). Similarly, in the treatment of $E$. coli infection, especially chitin can increase the ability of immune cells to produce interleuking (IL)-10, tumour necrosis factor (TNF) $\alpha$, interferon (IFN) $\gamma$, and IL-5, thereby helping to fight the infection (Ghotloo et al., 2015; Hoseini et al., 2016). Also, successful treatment of $E$. papillata infection with chitosan coincided with a strong effect on the immunity of mice, with increased neutrophil infiltration and levels of inflammatory cytokine transcription, and decreased levels of anti-inflammatory cytokine transcription. (Abdel-Latif et al., 2016). These data on the immunomodulatory effects of chitin and chitosan have been further confirmed by in vitro studies as shown in this paragraph. Through numerous studies with human and mice cells, it has become clear that there are certain receptors on immune cells that can recognise chitin and chitosan and allow cells to react to their presence. In particular galactin-3, mannose receptor, RegIII $\gamma$, dectin-1, and various toll like receptors have been shown to interact with chitin and/or chitosan (Komi et al., 2018). The typical immune cells that express most, if not all, of these receptors are macrophages. Studies on direct exposure of macrophages to chitin or chitosan have shown that this leads to cytokine production similar to the above (i.e. IL-10, IL-6, and TNF $\alpha$ ) (Wagener et al., 2014). In addition, spleen derived immune cell mixtures responded to chitin exposure with the production of IFN $\gamma$, IL-12, and TNF $\alpha$ (Shibata et al., 1997). Mainly through in vitro studies, it has also become clear that various physical and chemical parameters are critical to the functions of chitin and chitosan. Purity, size, concentration, and acetylation level are all factors that have been individually shown to affect the strength or type of immunomodulatory effects of chitin and chitosan. (Alvarez, 2014; Zimmerman, 2014).

\section{Antioxidant activity}

Oxidation of cellular components is linked to several adverse health conditions (Halliwell, 2012). Reactive oxygen species (ROS) responsible for this, can be generated endogenously, as a response to stress or pathogens, or exogenously via toxins or UV exposure. Production of ROS as protection against invaders is an effective mechanism, although excess production can lead to undesired tissue damage. Antioxidants can therefore be beneficial to protect against exogenous influences, as well as minimising collateral damage. Antioxidants can neutralise free radicals as well as reactive oxygen species (that are responsible for oxidative damage) via three mechanisms: hydrogen atom transfer, electron-proton transfer, or sequential proton loss-electron transfer (Chen et al., 2015). Several reports have highlighted the antioxidant potential of insect proteins such as those from Acheta domesticus (L.) (Orthoptera: Gryllidae), BSF, and T. molitor proteins (Mouithys-Mickalad et al., 2020; Navarro del Hierro et al., 2020). Some authors have also reported strong radical scavenging activities of protein hydrolysates from these insect species (MouithysMickalad et al., 2020; Zielińska et al., 2017a,b, 2018). Oxidative damage of cellular components could occur via several pathways. One of the noticeable pathways involve neutrophil response. Animals are continuously exposed to pathogenic microbes via the oral route (Mouithys-Mickalad et al., 2020). When the pathogenic microbes enter the animal body, neutrophils (and other white blood cells) rush to the site of infestation and initiate a defence via phagocytosis, degranulation, and release of the neutrophil extracellular trap. These processes result in development of reactive oxygen species (e.g. superoxide anion) and enzymes that facilitate oxidation (e.g. myeloperoxidase). This whole process is crucial for the host defence. However, continuous exposure of microbes results in excessive secretion of the oxidative molecules which can cause inflammatory damage to cellular components. In the long run, these oxidative damages could even result in the formation of inflammatory diseases, such as accelerated ageing, locomotor malfunctioning, etc. (Beckman et al., 1990; Lobo et al., 2010; Tsumbu et al., 2012). In vitro antioxidant activity of BSF protein derivatives against neutrophil and myeloperoxidase response has been reported in detail. Authors indicated that BSF proteins and protein hydrolysates could be effective in preventing the oxidative damage that results from the neutrophil response, whereas fishmeal and chicken meal used as benchmark during the study exhibit little to no activity (at highest concentration analysed). During the same study, authors indicated that BSF proteins and protein hydrolysates also exhibit strong potential to prevent oxidative damage resulting from myeloperoxidase response, whereas fishmeal and chicken meal used in this study exhibit mild pro-oxidant activity (Mouithys-Mickalad et al., 2020). This activity could be attributed to the presence of antioxidant peptides (Mouithys-Mickalad et al., 2020; Zielińska et al., 2017a,b, 2018). The antioxidant activity of peptides depends on several factors, including: (1). Molecular weight, with short chain peptides being more effective in scavenging free radicals; (2). Amino acid composition as hydrophobic amino acids exhibit higher free radical scavenging activity when compared to hydrophilic amino acids; (3). Amino acid sequence as amphiphilic peptides have superior radical scavenging activity (Cai et al., 2015; Yang et al., 2019; Zou et al., 2016). In context of molecular weight, BSF protein derivatives contain a substantial amount of proteins $<1000$ da (6 and $98 \%$ of total proteins in BSF proteins and protein hydrolysates, respectively) (Mouithys-Mickalad et al., 2020). Furthermore, BSF also contain substantial amounts of hydrophobic amino acids (Spranghers et al., 2017). There is still limited information regarding the presence of amphiphilic peptides in BSF and this could be a subject of 
future investigations. Most researchers have used water soluble extracts for the determination of in vitro antioxidant activity of insect proteins (Chatsuwan et al., 2018; Di Mattia et al., 2019; Flores et al., 2020; Mouithys-Mickalad et al., 2020). Water soluble short chain peptides (present in substantial quantities in insects like BSF) could be readily absorbed in the intestines of monogastric animals (Wang et al., 2019). There are several in vivo studies that report strong antioxidant activity of insect proteins in fish and poultry diets (Chu et al., 2020; Li et al., 2017; Xu et al., 2020). However, there is a scarcity of literature that reports the in vivo antioxidant potential of insect proteins in monogastric diets. A study on $E$. coli lipopolysaccharide challenged beagle dogs indicated improvement in glutathione peroxidase and superoxide dismutase concentrations in the body with increased dietary BSF proteins. This indicates antioxidant potential of insect proteins in monogastric animals (Lei et al., 2019). However, studies are still needed to further validate these findings and justify the antioxidant activity of insect proteins in farmed monogastric animals such as pigs, rabbits, etc.

\section{Summary and conclusion}

Insects can fulfil a major role in upgrading the value of side streams or leftovers into high-value feed ingredients in a circular economy. Insects and products derived from insects are rich sources of macro-nutrients such as protein and fat, but also other important nutrients such as monounsaturated and/or poly-unsaturated fatty acids, copper, iron, magnesium, manganese, phosphorous, selenium, and zinc, as well as riboflavin, pantothenic acid, biotin, and in some cases folic acid. Next to nutritional value, insects also contain bioactive compounds contributing to possible secondary effects of health stimulators in livestock animals. Three categories of bioactive compounds in insects are included in animal research regularly: AMPs, fatty acids (especially lauric acid), and polysaccharides (especially chitin and chitosan). Each compound demonstrated antimicrobial activities via different mechanism(s) including membrane pore formation or destruction, impeding intracellular processes or $\mathrm{pH}$, or supporting the immune system of the host. Moreover, antioxidant capacity of insectproteins might also protect against oxidative tissue damage. There are several ways to feed bioactive insect components to farm animals. Insect larvae can be fed live, but they can also be further processed into insect protein and insect fat and subsequently be included in the feed. Bioactive insect components can also be extracted but this will increase the costs of these components, while the combination of AMP complexe), and thus the combination of AMPs with fatty acids and chitin or chitosan seems to be the solution against antimicrobial resistance. This might perhaps be the main advantage of insects over individual antibiotics for the future to combat antibiotic resistance. More research into health-promoting properties of bioactive insect components such as e.g. processing or rearing on health-promoting effects, optimal inclusion levels, and differences in efficacy between insects species is therefore recommended in the near future to create added value from insect products in animal feed.

\section{Acknowledgement}

This research (TKI number: AF16178) was commissioned and funded by the Top Sector Alliance for Knowledge and Innovation (TKI) along with private partners ABZ Diervoeding, Nutrition Sciences, Protix, and Provimi B.V and also funded by the 'Healthy and Safe Food System knowledge base program of the Dutch Ministry of Agriculture, Nature, and Food Quality KB-37-001-007). The authors would like to thank Prof. Dr H.J. Wichers, Wageningen University and Research, Fresh food and Chains and the members of the TKI consortium for their constructive comments on a previous version of the manuscript.

\section{Conflict of interest}

The authors declare no conflict of interest

\section{References}

Abdel-Latif, M., Abdel-Haleem, H.M. and Abdel-Baki, A.-A.S., 2016. Anticoccidial activities of chitosan on Eimeria papillata-infected mice. Parasitology Research 115: 2845-2852.

Alvarez, F.J., 2014. The effect of chitin size, shape, source and purification method on immune recognition. Molecules 19: 44334451.

Andersen, A.S., Sandvang, D., Schnorr, K.M., Kruse, T., Neve, S., Joergensen, B., Karlsmark, T. and Krogfelt, K.A., 2010. A novel approach to the antimicrobial activity of maggot debridement therapy. Journal of Antimicrobial Chemotherapy 65: 1646-1654.

Beckman, J.S., Beckman, T.W., Chen, J., Marshall, P.A. and Freeman, B.A., 1990. Apparent hydroxyl radical production by peroxynitrite: implications for endothelial injury from nitric oxide and superoxide. Proceedings of the National Academy of Sciences 87: 1620-1624.

Bovera, F., Loponte, R., Marono, S., Piccolo, G., Parisi, G., Iaconisi, V., Gasco, L. and Nizza, A., 2016. Use of Tenebrio molitor larvae meal as protein source in broiler diet: effect on growth performance, nutrient digestibility, and carcass and meat traits. Journal of Animal Science 94: 639-647.

Bovera, F., Loponte, R., Pero, M.E., Cutrignelli, M.I., Calabrò, S., Musco, N., Vassalotti, G., Panettieri, V., Lombardi, P., Piccolo, G., Di Meo, C., Siddi, G., Fliegerova, K. and Moniello, G., 2018. Laying performance, blood profiles, nutrient digestibility and inner organs traits of hens fed an insect meal from Hermetia illucens larvae. Research in Veterinary Science 120: 86-93.

Bovera, F., Piccolo, G., Gasco, L., Marono, S., Loponte, R. and Vassalotti, G., 2015. Yellow mealworm larvae (Tenebrio molitor L.) as a possible alternative to soybean meal in broiler diets. British Poultry Science 56(5): 569-575. 
Bulet, P., Charlet, M. and Hetru, C., 2003. Antimicrobial peptides in insect immunity. In: Ezekowitz, R.A.B. and Hoffmann, J.A. (eds.) Innate immunity. Humana Press, Totowa, NJ, USA, pp. 89-107.

Bulet, P., Dimarcq, J.L., Hetru, C., Lagueux, M., Charlet, M., Hegy, G., Van Dorsselaer, A. and Hoffmann, J.A., 1993. A novel inducible antibacterial peptide of Drosophila carries an O-glycosylated substitution. Journal of Biological Chemistry 268: 14893-14897.

Cai, L., Wu, X., Zhang, Y., Li, X., Ma, S. and Li, J., 2015. Purification and characterization of three antioxidant peptides from protein hydrolysate of grass carp (Ctenopharyngodon idella) skin. Journal of Functional Foods 16: 234-242.

Carlsson, A., Nyström, T., De Cock, H. and Bennich, H., 1998. Attacin - an insect immune protein - binds LPS and triggers the specific inhibition of bacterial outer-membrane protein synthesis. Microbiology 144: 2179-2188.

Chapuisat, M., Oppliger, A., Magliano, P. and Christe, P., 2007. Wood ants use resin to protect themselves against pathogens. Proceedings of the Royal Society B: Biological Sciences 274: 2013-2017.

Charroux, B., Rival, T., Narbonne-Reveau, K. and Royet, J., 2009. Bacterial detection by Drosophila peptidoglycan recognition proteins. Microbes and Infection 11: 631-636.

Chatsuwan, N., Nalinanon, S., Puechkamut, Y., Lamsal, B.P. and Pinsirodom, P., 2018. Characteristics, functional properties, and antioxidant activities of water-soluble proteins extracted from grasshoppers, Patanga succincta and Chondracris roseapbrunner. Journal of Chemistry, Article ID: 6528312.

Chen, G.-L., Chen, S.-G., Xie, Y.-Q., Chen, F., Zhao, Y.-Y., Luo, C.-X. and Gao, Y.-Q., 2015. Total phenolic, flavonoid and antioxidant activity of 23 edible flowers subjected to in vitro digestion. Journal of Functional Foods 17: 243-259.

Chernysh, S., Gordya, N. and Suborova, T., 2015. Insect antimicrobial peptide complexes prevent resistance development in bacteria. PLoS ONE 10(7): e0130788. https://doi.org/10.1371/journal.pone.0130788

Choi, S.C., Ingale, S.L., Kim, J.S., Park, Y.K., Kwon, I.K. and Chae, B.J., 2013a. An antimicrobial peptide-A3: effects on growth performance, nutrient retention, intestinal and faecal microflora and intestinal morphology of broilers. British Poultry Science 54: 738-746.

Choi, S.C., Ingale, S.L., Kim, J.S., Park, Y.K., Kwon, I.K. and Chae, B.J., 2013b. Effects of dietary supplementation with an antimicrobial peptide-P5 on growth performance, nutrient retention, excreta and intestinal microflora and intestinal morphology of broilers. Animal Feed Science and Technology 185: 78-84.

Chu, X., Li, M., Wang, G., Wang, K., Shang, R., Wang, Z. and Li, L., 2020. Evaluation of the low inclusion of full-fatted Hermetia illucens larvae meal for layer chickens: growth performance, nutrient digestibility, and gut health. Frontiers in Veterinary Science 7: 585843.

Cutter, C.N. and Sumner, S.S., 2002. Application of edible coatings on muscle foods. Protein-based films and coatings. CRC Press, Boca Raton, FL, USA, pp. 467-484.

Di Mattia, C., Battista, N., Sacchetti, G. and Serafini, M., 2019. Antioxidant activities in vitro of water and liposoluble extracts obtained by different species of edible insects and invertebrates. Frontiers in Nutrition 6: 106.
Dong, L., Ariëns, R.M.C., Tomassen, M.M., Wichers, H.J. and Govers, C., 2020. In vitro studies toward the use of chitin as nutraceutical: impact on the intestinal epithelium, macrophages, and microbiota. Molecular Nutrition \& Food Research 64: 2000324, https://doi. org/10.1002/mnfr.202000324

Dong, L., Wichers, H.J. and Govers, C., 2019. Beneficial health effects of chitin and chitosan. In: Van den Broek, L.A.M. and Boeriu, C.G. (eds.) Chitin and chitosan. Wiley, Hoboken, NJ, USA, pp. 145-167. https://doi.org/10.1002/9781119450467.ch6

Dörper, A., Veldkamp, T. and Dicke, M., 2021. Use of black soldier fly and housefly in feed to promote sustainable poultry production. Journal of Insects as Food and Feed 7 (5): 761-780. https://doi. org/10.3920/JIFF2020.0064

Duclohier, H., 2002. How do channel- and pore-forming helical peptides interact with lipid membranes and how does this account for their antimicrobial activity? Mini-Reviews in Medicinal Chemistry 2: 331-342.

Dushay, M.S., Roethele, J.B., Chaverri, J.M., Dulek, D.E., Syed, S.K., Kitami, T. and Eldon, E.D., 2000. Two attacin antibacterial genes of Drosophila melanogaster. Gene 246: 49-57.

Duvic, B., Jouan, V., Essa, N., Girard, P.A., Pages, S., Abi Khattar, Z., Volkoff, N.A., Givaudan, A., Destoumieux-Garzon, D. and Escoubas, J.M., 2012. Cecropins as a marker of Spodoptera frugiperda immunosuppression during entomopathogenic bacterial challenge. Journal of Insect Physiology 58: 881-888.

Flores, D.R., Casados, L.E., Velasco, S.F., Ramírez, A.C. and Velázquez, G., 2020. Comparative study of composition, antioxidant and antimicrobial activity of two adult edible insects from Tenebrionidae family. BMC Chemistry 14: 55.

Food and Agriculture Organization (FAO), 2016. The FAO action plan on antimicrobial resistance 2016-2020. FAO, Rome, Italy.

Gasco, L., Finke, M. and Van Huis, A., 2018. Can diets containing insects promote animal health? Journal of Insects as Food and Feed 4: 1-4.

Geng, H., An, C.-J., Hao, Y.-J., Li, D.-S. and Du, R.-Q., 2004. Molecular cloning and expression of attacin from housefly (Musca domestica). Acta Genetica Sinica 31: 1344-1350.

Ghotloo, S., Hoseini, M.H.M., Alimohammadian, M.H., Khaze, V., Memarnejadian, A. and Rostami, A., 2015. Immunomodulatory effects of chitin microparticles on Leishmania major-infected BALB/c mice. Parasitology International 64: 219-221.

Griminger, P. and Scanes, C.G., 1986. Protein metabolism. In: Sturkie, P.D. (ed.) Avian physiology. Springer, New York, New York, NY, USA, pp. 326-344.

Guillot, E., Vaugelade, P., Lemarchali, P. and Re Rat, A., 1993. Intestinal absorption and liver uptake of medium-chain fatty acids in nonanaesthetized pigs. British Journal of Nutrition 69: 431-442.

Halliwell, B., 2012. Free radicals and antioxidants: updating a personal view. Nutrition Reviews 70: 257-265.

Hansen, A., Schäfer, I., Knappe, D., Seibel, P. and Hoffmann, R., 2012. Intracellular toxicity of proline-rich antimicrobial peptides shuttled into mammalian cells by the cell-penetrating peptide penetratin. Antimicrobial Agents and Chemotherapy 56: 5194-5201. 
Hoseini, M.H.M., Moradi, M., Alimohammadian, M.H., Shahgoli, V.K., Darabi, H. and Rostami, A., 2016. Immunotherapeutic effects of chitin in comparison with chitosan against Leishmania major infection. Parasitology International 65: 99-104.

Hossain, S. and Blair, R., 2007. Chitin utilization by broilers and its effect on body composition and blood metabolites. British Poultry Science 48(1): 33-38. https://doi.org/10.1080/00071660601156529

Hu, F., Gao, X., She, R., Chen, J., Mao, J., Xiao, P. and Shi, R., 2017. Effects of antimicrobial peptides on growth performance and small intestinal function in broilers under chronic heat stress. Poultry Science 96: 798-806.

Imamura, M., Wada, S., Ueda, K., Saito, A., Koizumi, N., Iwahana, H. and Sato, R., 2009. Multipeptide precursor structure of acaloleptin A isoforms, antibacterial peptides from the Udo longicorn beetle, Acalolepta luxuriosa. Developmental \& Comparative Immunology 33: 1120-1127.

Islam, M.M. and Yang, C.-J., 2017. Efficacy of mealworm and super mealworm larvae probiotics as an alternative to antibiotics challenged orally with Salmonella and E. coli infection in broiler chicks. Poultry Science 96: 27-34.

Islam, S., Bhuiyan, M.A.R. and Islam, M.N., 2017. Chitin and chitosan: structure, properties and applications in biomedical engineering. Journal of Polymers and the Environment 25: 854-866.

Jin, X., Mei, H., Li, X., Ma, Y., Zeng, A.H., Wang, Y., Lu, X., Chu, F., Wu, Q. and Zhu, J., 2010. Apoptosis-inducing activity of the antimicrobial peptide cecropin of Musca domestica in human hepatocellular carcinoma cell line BEL-7402 and the possible mechanism. Acta Biochimica et Biophysica Sinica 42: 259-265.

Jozefiak, A. and Engberg, R.M., 2017. Insect proteins as a potential source of antimicrobial peptides in livestock production. A review. Journal of Animal and Feed Sciences 26: 87-99.

Jozefiak, D., Jozefiak, A., Kieronczyk, B., Rawski, M., Swiatkiewicz, S., Dlugosz, J. and Engberg, R.M., 2016. Insects - a natural nutrient source for poultry - a review. Annals of Animal Science 16: 297-313.

Kabara, J.J., Swieczkowski, D.M., Conley, A.J. and Truant, J.P., 1972. Fatty acids and derivatives as antimicrobial agents. Antimicrobial Agents and Chemotherapy 2: 23-28.

Kang, J.K., Hwang, J.S., Nam, H.J., Ahn, K.J., Seok, H., Kim, S.-K., Yun, E.Y., Pothoulakis, C., Lamont, J.T. and Kim, H., 2011. The insect peptide coprisin prevents Clostridium difficile-mediated acute inflammation and mucosal damage through selective antimicrobial activity. Antimicrobial Agents and Chemotherapy 55: 4850-4857.

Khempaka, S., Chitsatchapong, C. and Molee, W., 2011. Effect of chitin and protein constituents in shrimp head meal on growth performance, nutrient digestibility, intestinal microbial populations, volatile fatty acids, and ammonia production in broilers. Journal of Applied Poultry Research 20: 1111. https://doi.org/10.3382/ japr.2010-00162

Koide, S.S., 1998. Chitin-chitosan: properties, benefits and risks. Nutrition Research 18: 1091-1101.

Komi, D.E.A., Sharma, L. and Dela Cruz, C.S., 2018. Chitin and its effects on inflammatory and immune responses. Clinical Reviews in Allergy \& Immunology 54: 213-223.
Kragol, G., Hoffmann, R., Chattergoon, M.A., Lovas, S., Cudi, C.M., Bulet, P., Condie, B.A., Rosengren, K.J., Montaner, L.J. and Otvos, L., 2002. Identification of crucial residues for the antibacterial activity of the proline-rich peptide, pyrrhocoricin. European Journal of Biochemistry 269: 4226-4237.

Kragol, G., Lovas, S., Varadi, G., Condie, B.A., Hoffmann, R. and Otvos Jr, L., 2001. The antibacterial peptide pyrrhocoricin inhibits the ATPase actions of DnaK and prevents chaperone-assisted protein folding. Biochemistry 40: 3016-3026.

Lee, C.G., Da Silva, C.A., Lee, J.-Y., Hartl, D. and Elias, J.A., 2008. Chitin regulation of immune responses: an old molecule with new roles. Current Opinion in Immunology 20: 684-689.

Lee, J.Y., Boman, A., Sun, C.X., Andersson, M., Jörnvall, H., Mutt, V. and Boman, H.G., 1989. Antibacterial peptides from pig intestine: isolation of a mammalian cecropin. Proceedings of the National Academy of Sciences of the USA 86: 9159-9162.

Lee, K.H., Hong, S.Y. and Oh, J.E., 1998. Synthesis and structurefunction study about tenecin 1, an antibacterial protein from larvae of Tenebrio molitor. Febs Letters 439: 41-45.

Lee, V.S., Tu, W.C., Jinn, T.R., Peng, C.C., Lin, L.J. and Tzen, J.T., 2007. Molecular cloning of the precursor polypeptide of mastoparan B and its putative processing enzyme, dipeptidyl peptidase IV, from the black-bellied hornet, Vespa basalis. Insect Molecular Biology 16: 231-237.

Lei, X.J., Kim, T.H., Park, J.H. and Kim, I.H., 2019. Evaluation of supplementation of defatted black soldier fly (Hermetia illucens) larvae meal in Beagle dogs. Annals of Animal Science 19: 767-777.

Li, S., Ji, H., Zhang, B., Zhou, J. and Yu, H., 2017. Defatted black soldier fly (Hermetia illucens) larvae meal in diets for juvenile Jian carp (Cyprinus carpio var. Jian): growth performance, antioxidant enzyme activities, digestive enzyme activities, intestine and hepatopancreas histological structure. Aquaculture 477: 62-70.

Li, W.-F., Ma, G.-X. and Zhou, X.-X., 2006. Apidaecin-type peptides: biodiversity, structure-function relationships and mode of action. Peptides 27: 2350-2359.

Li, Y., Xiang, Q., Zhang, Q., Huang, Y. and Su, Z., 2012. Overview on the recent study of antimicrobial peptides: origins, functions, relative mechanisms and application. Peptides 37: 207-215.

Lieberman, S., Enig, M.G. and Preuss, P.H.G., 2006. A review of monolaurin and lauric acid: natural virucidal and bactericidal agents. Alternative and Complementary Therapies 12: 310-314.

Liu, S., Wang, F., Tang, L., Gui, W., Cao, P., Liu, X., Poon, A.W.-S., Shaw, P.-C. and Jiang, T., 2007. Crystal structure of mastoparan from Polistes jadwagae at $1.2 \AA$ resolution. Journal of Structural Biology 160: 28-34.

Liu, Y., 2015. Fatty acids, inflammation and intestinal health in pigs. Journal of Animal Science and Biotechnology 6: 41. https://doi. org/10.1186/s40104-015-0040-1

Llor, C. and Bjerrum, L., 2014. Antimicrobial resistance: risk associated with antibiotic overuse and initiatives to reduce the problem. Therapeutic Advances in Drug Safety 5: 229-241.

Lobo, V., Patil, A., Phatak, A. and Chandra, N., 2010. Free radicals, antioxidants and functional foods: impact on human health. Pharmacognosy Reviews 4: 118. 
Loponte, R., Nizza, S., Bovera, F., De Riu, N., Fliegerova, K., Lombardi, P., Vassalotti, G., Mastellone, V., Nizza, A. and Moniello, G., 2017. Growth performance, blood profiles and carcass traits of Barbary partridge (Alectoris barbara) fed two different insect larvae meals (Tenebrio molitor and Hermetia illucens). Research in Veterinary Science 115: 183-188.

Makkar, H.P.S., Tran, G., Henze, V. and Ankers, P., 2014. State-ofthe-art on use of insects as animal feed. Animal Feed Science and Technology 197: 1-33.

Marono, S., Loponte, R., Lombardi, P., Vassalotti, G., Pero, M.E., Russo, F., Gasco, L., Parisi, G., Piccolo, G., Nizza, S., Di Meo, C., Attia, Y.A. and Bovera, F., 2017. Productive performance and blood profiles of laying hens fed Hermetia illucens larvae meal as total replacement of soybean meal from 24 to 45 weeks of age. Poultry Science 96: 1783-1790.

Matsue, M., Mori, Y., Nagase, S., Sugiyama, Y., Hirano, R., Ogai, K., Ogura, K., Kurihara, S. and Okamoto, S., 2019. Measuring the antimicrobial activity of lauric acid against various bacteria in human gut microbiota using a new method. Cell Transplantation 28: 096368971988136.

Mattiuzzo, M., Bandiera, A., Gennaro, R., Benincasa, M., Pacor, S., Antcheva, N. and Scocchi, M., 2007. Role of the Escherichia coli SbmA in the antimicrobial activity of proline-rich peptides. Molecular Microbiology 66: 151-163.

Mau-Chang, C., Horng-Chin, Y.G. and Been-Huang, C., 1996. Antimicrobial and physicochemical properties of methylcellulose and chitosan films containing a preservative Journal of Food Processing and Preservation 20: 379-390.

Meylaers, K., Cerstiaens, A., Vierstraete, E., Baggerman, G., Michiels, C.W., De Loof, A. and Schoofs, L., 2003. Antimicrobial compounds of low molecular mass are constitutively present in insects: characterisation of beta-alanyl-tyrosine. Current Pharmaceutical Design 9: 159-174.

Moon, H.J., Lee, S.Y., Kurata, S., Natori, S. and Lee, B.L., 1994. Purification and molecular cloning of cDNA for an inducible antibacterial protein from larvae of the Coleopteran, Tenebrio molitor. The Journal of Biochemistry 116: 53-58.

Moon, J.S., Kim, H.K., Koo, H.C., Joo, Y.S., Nam, H.M., Park, Y.H. and Kang, M.I., 2007. The antibacterial and immunostimulative effect of chitosan-oligosaccharides against infection by Staphylococcus aureus isolated from bovine mastitis. Applied Microbiology and Biotechnology 75: 989-998.

Mouithys-Mickalad, A., Schmitt, E., Dalim, M., Franck, T., Tome, N.M., Van Spankeren, M., Serteyn, D. and Paul, A., 2020. Black soldier fly (Hermetia illucens) larvae protein derivatives: potential to promote animal health. Animals 10: 941.

Navarro del Hierro, J., Gutiérrez-Docio, A., Otero, P., Reglero, G. and Martin, D., 2020. Characterization, antioxidant activity, and inhibitory effect on pancreatic lipase of extracts from the edible insects Acheta domesticus and Tenebrio molitor. Food Chemistry 309: 125742.

Nicolas, P., 2009. Multifunctional host defense peptides: intracellulartargeting antimicrobial peptides. The FEBS Journal 276: 6483-6496.

Otvos, J.L., 2000. Antibacterial peptides isolated from insects. Journal of Peptide Science 6: 497-511.
Otvos Jr, L., 2002. The short proline-rich antibacterial peptide family. Cellular and Molecular Life Sciences 59: 1138-1150.

Park, B.K. and Kim, M.-M., 2010. Applications of chitin and its derivatives in biological medicine. International Journal of Molecular Sciences 11: 5152-5164.

Park, S.-I., Kim, J.-W. and Yoe, S.M., 2015. Purification and characterization of a novel antibacterial peptide from black soldier fly (Hermetia illucens) larvae. Developmental \& Comparative Immunology 52: 98-106.

Park, S.I., Chang, B.S. and Yoe, S.M., 2014. Detection of antimicrobial substances from larvae of the black soldier fly, Hermetia illucens (Diptera: Stratiomyidae). Entomological Research 44: 58-64.

Park, S.I. and Hahm, K.S., 2005. Antimicrobial peptides (AMPs): peptide structure and mode of action. Biochemistry \& Molecular Biology Journal 38: 766.

Rahnamaeian, M., Cytryńska, M., Zdybicka-Barabas, A., Dobslaff, K., Wiesner, J., Twyman, R.M., Zuchner, T., Sadd, B.M., Regoes, R.R., Schmid-Hempel, P. and Vilcinskas, A., 2015. Insect antimicrobial peptides show potentiating functional interactions against Gramnegative bacteria. Proceedings of the Royal Society B: Biological Sciences 282: 20150293.

Ricke, S.C., 2003. Perspectives on the use of organic acids and short chain fatty acids as antimicrobials. Poultry Science 82: 632-639.

Rossi, R., Pastorelli, G., Cannata, S. and Corino, C., 2010. Recent advances in the use of fatty acids as supplements in pig diets: a review. Animal Feed Science and Technology 162: 1-11.

Roth, F.X. and Kirchgessner, M., 1998. Organic acids as feed additives for young pigs: nutritional and gastrointestinal effects. Journal of Animal and Feed Sciences 7: 25-33.

Rumpold, B.A. and Schlüter, O.K., 2013. Nutritional composition and safety aspects of edible insects. Molecular Nutrition \& Food Research 57: 802-823.

Sanchez-Muros, M.J., Barroso, F.G. and Manzano-Agugliaro, F., 2014. Insect meal as renewable source of food for animal feeding: a review. Journal of Cleaner Production 65: 16-27.

Schmitt, P., Rosa, R.D. and Destoumieux-Garzón, D., 2016. An intimate link between antimicrobial peptide sequence diversity and binding to essential components of bacterial membranes. Biochimica et Biophysica Acta (BBA) - Biomembranes 1858: 958-970.

Scocchi, M., Tossi, A. and Gennaro, R., 2011. Proline-rich antimicrobial peptides: converging to a non-lytic mechanism of action. Cellular and Molecular Life Sciences 68: 2317-2330.

Shibata, Y., Metzger, W.J. and Myrvik, Q.N., 1997. Chitin particleinduced cell-mediated immunity is inhibited by soluble mannan: mannose receptor-mediated phagocytosis initiates IL-12 production. The Journal of Immunology 159: 2462-2467.

Simjee, S., White, D.G., Meng, J., Wagner, D.D., Qaiyumi, S., Zhao, S., Hayes, J.R. and McDermott, P.F., 2002. Prevalence of streptogramin resistance genes among Enterococcus isolates recovered from retail meats in the Greater Washington DC area. Journal of Antimicrobial Chemotherapy 50: 877-882.

Skřivanová, E., Marounek, M., Dlouhá, G. and Kaňka, J., 2005. Susceptibility of Clostridium perfringens to C2-C18 fatty acids. Letters in Applied Microbiology 41: 77-81. 
Spranghers, T., Michiels, J., Vrancx, J., Ovyn, A., Eeckhout, M., De Clercq, P. and De Smet, S., 2018. Gut antimicrobial effects and nutritional value of black soldier fly (Hermetia illucens L.) prepupae for weaned piglets. Animal Feed Science and Technology 235: 33-42. Spranghers, T., Ottoboni, M., Klootwijk, C., Ovyn, A., Deboosere, S., De Meulenaer, B., Michiels, J., Eeckhout, M., De Clercq, P. and De Smet, S., 2017. Nutritional composition of black soldier fly (Hermetia illucens) prepupae reared on different organic waste substrates. Journal of the Science of Food and Agriculture 97: 2594-2600.

St-Hilaire, S., Cranfill, K., McGuire, M.A., Mosley, E.E., Tomberlin, J.K., Newton, L., Sealey, W., Sheppard, C. and Irving, S., 2007. Fish offal recycling by the black soldier fly produces a foodstuff high in omega-3 fatty acids. Journal of the World Aquaculture Society 38: 309-313.

Steiner, H., Hultmark, D., Engstrom, A., Bennich, H. and Boman, H.G., 1981. Sequence and specificity of two antibacterial proteins involved in insect immunity. Nature 292: 246-248.

Suyatma, N.E., Copinet, A., Tighzert, L. and Coma, V., 2004. Mechanical and barrier properties of biodegradable films made from chitosan and poly (lactic acid) blends. Journal of Polymers and the Environment 12: 1-6.

Suzuki, K., Okawa, Y., Hashimoto, K., Suzuki, S. and Suzuki, M., 1984. Protecting effect of chitin and chitosan on experimentally induced murine candidiasis. Microbiology and Immunology 28: 903-912.

Tanaka, H., Yamamoto, M., Moriyama, Y., Yamao, M., Furukawa, S., Sagisaka, A., Nakazawa, H., Mori, H. and Yamakawa, M., 2005. A novel Rel protein and shortened isoform that differentially regulate antibacterial peptide genes in the silkworm Bombyx mori. Biochimica et Biophysica Acta 1730: 10-21.

Thevissen, K., Warnecke, D., François, I., Leipelt, M., Heinz, E., Ott, C., Zaehringer, U., Thomma, B., Ferket, K. and Cammue, B., 2004. Defensins from insects and plants interact with fungal glucosylceramides. Journal of Biological Chemistry 279: 3900-3905.

Torres, A.M. and Kuchel, P.W., 2004. The beta-defensin-fold family of polypeptides. Toxicon 44: 581-588.

Tsumbu, C.N., Deby-Dupont, G., Tits, M., Angenot, L., Frederich, M., Kohnen, S., Mouithys-Mickalad, A., Serteyn, D. and Franck, T., 2012. Polyphenol content and modulatory activities of some tropical dietary plant extracts on the oxidant activities of neutrophils and myeloperoxidase. International Journal of Molecular Sciences 13: 628-650.

Van Boeckel, T.P., Brower, C., Gilbert, M., Grenfell, B.T., Levin, S.A., Robinson, T.P., Teillant, A. and Laxminarayan, R., 2015. Global trends in antimicrobial use in food animals. Proceedings of the National Academy of Sciences of the USA 112: 5649-5654.

Van Huis, A. and Oonincx, D.G.A.B., 2017. The environmental sustainability of insects as food and feed. A review. Agronomy for Sustainable Development 37: 43.

Vartiainen, J., Motion, R., Kulonen, H., Rättö, M., Skyttä, E. and Ahvenainen, R., 2004. Chitosan-coated paper: effects of nisin and different acids on the antimicrobial activity. Journal of Applied Polymer Science 94: 986-993.
Veldkamp, T., Duinkerken, G., Van Huis, A., Lakemond, C.M.M., Ottevanger, E., Bosch, G. and Van Boekel, M.A.J.S., 2012. Insects as a sustainable feed ingredient in pig and poultry diets - a feasibility study. Wageningen UR Livestock Research, Wageningen, the Netherlands.

Viljakainen, L. and Pamilo, P., 2008. Selection on an antimicrobial peptide defensin in ants. Journal of Molecular Evolution 67: 643-652.

Wagener, J., Malireddi, R.S., Lenardon, M.D., Köberle, M., Vautier, S., MacCallum, D.M., Biedermann, T., Schaller, M., Netea, M.G. and Kanneganti, T.-D., 2014. Fungal chitin dampens inflammation through IL-10 induction mediated by NOD2 and TLR9 activation. PLoS Pathogens 10: e1004050.

Wang, B., Xie, N. and Li, B., 2019. Influence of peptide characteristics on their stability, intestinal transport, and in vitro bioavailability: a review. Journal of Food Biochemistry 43: e12571.

Wang, S., Zeng, X., Yang, Q. and Qiao, S., 2016. Antimicrobial peptides as potential alternatives to antibiotics in food animal industry. International Journal of Molecular Sciences 17: 603.

Wen, L.-F. and He, J.-G., 2012. Dose-response effects of an antimicrobial peptide, a cecropin hybrid, on growth performance, nutrient utilisation, bacterial counts in the digesta and intestinal morphology in broilers. British Journal of Nutrition 108: 1756-1763.

Wimley, W.C., 2010. Describing the mechanism of antimicrobial peptide action with the interfacial activity model. ACS Chemical Biology 5: 905-917.

Wu, S., Wang, J., Zhu, L., Ren, H. and Yang, X., 2020. A novel apidaecin Api-PR19 synergizes with the gut microbial community to maintain intestinal health and promote growth performance of broilers. Journal of Animal Science and Biotechnology 11: 61-61.

Xu, X., Ji, H., Yu, H. and Zhou, J., 2020. Influence of dietary black soldier fly (Hermetia illucens Linnaeus) pulp on growth performance, antioxidant capacity and intestinal health of juvenile mirror carp (Cyprinus carpio var. specularis). Aquaculture Nutrition 26: 432-443.

Yang, X.-R., Zhang, L., Ding, D.-G., Chi, C.-F., Wang, B. and Huo, J.-C., 2019. Preparation, identification, and activity evaluation of eight antioxidant peptides from protein hydrolysate of Hairtail (Trichiurus japonicas) muscle. Marine Drugs 17: 23.

Yi, H.-Y., Chowdhury, M., Huang, Y.-D. and Yu, X.-Q., 2014. Insect antimicrobial peptides and their applications. Applied Microbiology and Biotechnology 98: 5807-5822.

Zielińska, E., Baraniak, B. and Karaś, M., 2017a. Antioxidant and anti-inflammatory activities of hydrolysates and peptide fractions obtained by enzymatic hydrolysis of selected heat-treated edible insects. Nutrients 9: 970.

Zielińska, E., Baraniak, B. and Karaś, M., 2018. Identification of antioxidant and anti-inflammatory peptides obtained by simulated gastrointestinal digestion of three edible insects species (Gryllodes sigillatus, Tenebrio molitor, Schistocerca gragaria). International Journal of Food Science \& Technology 53: 2542-2551.

Zielińska, E., Karaś, M. and Jakubczyk, A., 2017b. Antioxidant activity of predigested protein obtained from a range of farmed edible insects. International Journal of Food Science \& Technology 52: 306-312. 


\section{T. Veldkamp et al.}

Zimmerman, J.R., 2014. The characterization of chitin microparticle preparations: degree of acetylation and its effect on immunologic response. MSc-thesis, University of Massachusetts, Amherst, MA, USA.
Zou, T.-B., He, T.-P., Li, H.-B., Tang, H.-W. and Xia, E.-Q., 2016. The structure-activity relationship of the antioxidant peptides from natural proteins. Molecules 21: 72 . 